\title{
THE SEISMIC RESPONSE OF NONSTRUCTURAL ELEMENTS IN BUILDINGS
}

\author{
C. Arnold1
} This paper was presented as a keynote address at the Pacific
Conference on Earthquake Engineering, Auckland, November 1991 .

\section{SUMMARY}

This paper reviews some current aspects of the problems of nonstructural earthquake damage and hazard mitigation. The paper reviews some of the axiomatic thinking about the problem and discusses some recent experience, primarily the Loma Prieta earthquake of 1989. A summing-up expresses some opinions and conclusions. One finding is that as long as the present seismic code philosophy continues, nonstructural damage, and in particular, considerable contents upset, will be sustained.

\section{INTRODUCTION}

This paper is divided into three parts. The first part provides a summary review of the nonstructural damage problem and is intended to reflect current axiomatic thinking. The second part provides some information on recent performance of nonstructural components focusing primarily, but not exclusively, on the San Francisco Bay Area Loma Prieta Earthquake of 1989. The third part presents some personal conclusions and observations on the problems and represents a summing-up based on available information and some direct observation.

The distinction between nonstructural and structural systems, components and elements is quite clear to most design professionals, and a number of definitions and lists exist. These may be based on function, position (eg interior or exterior) or the design process $[1,21$. The most useful type of categorization is probably to use traditional design responsibility, as expressed by the design consultant who is responsible for a group of components in the contract documents. This approach also reveals the important group of components that are added after building completion, such as furnishings, equipment, records, and inventories, generally defined as building contents.

While design professionals are clear about the structural/nonstructural distinction, almost everyone else concerned with aspects of building definition is not. This includes users and occupants, assessors, insurers, attorneys, and last but not least, nature herself. Once the building exists it acquires a total identity in which, contrary to the way in which engineers regard the building, most people regard the structure

$1 \begin{array}{llr}\text { President, } & \text { Building systems } \\ \text { Development, } & \text { Inc., San } \\ \text { California } & & \end{array}$

as the least important. Its load-bearing role is taken for granted and it is largely invisible compared to the user's interior surroundings and the outside observer's enjoyment, disgust, or indifference related to the exterior architecture. Nature, of course, pays no attention to our conceptual, professional, or legal distinctions.

\section{NONSTRUCTURAL DAMAGE}

\section{Introduction}

Earthquake damage to nonstructural items and building contents may result in economic losses, and possible death and injury to occupants. Total economic loss from nonstructural and contents performance failure can be many times the construction value of the building, because of loss of equipment, loss of inventory, and loss of use of the facility until it can regain its operational capabilities. Engineers tend to emphasize structural damage in earthquakes, but in certain situations earthquake damage to nonstructural components will greatly exceed the cost of structural damage.

For example, a recent analysis of a new 27-story condominium building in Los Angeles [3] estimated that in a Maximum Credible Event the building would suffer structural damage of just over $\$ 1$ million compared to non-structural damage of just under $\$ 6.7$ million, relative to a total present construction cost of $\$ 42.8$ million. This estimated cost is for direct economic loss only, excluding indirect losses of revenue and building use. Moreover, costly damage to nonstructural elements can occur in earthquakes of moderate intensities which would cause little or no structural damage.

The issues associated with seismic damage are summarized below. Four issues are related to the effects of damage, and a fifth issue relates to design and/or selection responsibility. 


\section{Life Hazard}

The life hazards presented by nonstructural components are of four kinds. These are,

Direct hazard - the possibility of casualties because of broken glass, light fixtures, appendages, etc.

Loss of critical function - casualties caused by loss of power to hospital life support systems in bed panels, or functional loss to fire, police or emergency service facilities.

Release of hazardous material - casualties caused by release of toxic chemicals, drugs, or radioactive materials.

Fire caused by nonstructural damage - damage to gas lines, electrical disruption, etc.

\section{Direct Economic Loss}

The direct cost of repairing nonstructural damage. Statistical information on this is lacking, primarily because normal methods of cost estimating and contracting do not make a distinction between structural and nonstructural. It is possible to allocate items in a detailed cost breakdown but this is time consuming, and has not been done on a publicly available basis.

\section{Loss of Building Function}

Nonstructural damage may cause loss of building function for a period of time, even in a building with little or no structural damage. Loss of function is the result of damage to components or systems necessary for useful function such as power and plumbing systems, or it may be due to disruption created by the repair of architectural or other nonstructural components.

\section{Btructura 1 Response Modification}

The nonstructural component may modify the structural response in ways detrimental to the safety of the building. Examples are the placing of heavy nonstructural partitions in locations that result in severe torsion and stress concentration, or the placement of nonstructural partitions between columns in such a way as to produce a short column condition. This can lead to column failure, distortion, and further nonstructural damage.

\section{Desian and/or selection Responsibility}

The nonstructural damage problem is particularly difficult to deal with because the non-structural components that are subject to seismic forces are not normally within the design scope of the structural engineer, whose responsibility it is to provide for the seismic safety of the building. His design work is typically confined to the building structure. In addition, nonstructural components - such as partition walls - are often added after the initial building design, and the original architect, or any architect at all, is often not involved. Finally, nonstructural equipment and furnishing is generally selected by those uninvolved in the building design.

From this summary it can be seen that the potential for damage is very great. For social, political, and economic reasons seismic codes have focused on the prevention of building collapse and consequent Iife loss. Reduction of property damage is not seen as a direct objective. Since, in a modern building, the structure only accounts for somewhere between $15-30 \%$ of building cost it is possible to have nonstructural damage costs that approach a substantial percentage of replacement cost, even though the structure meets the intent of the code.

So, in summary, damage to nonstructural components and contents involve the possibility of casualties, direct property loss, and indirect economic loss due to loss of function.

\section{The Nature of Nonstructural Damage}

Much of the reason for the complexity of nonstructural damage, both in cause, effects and analysis, is due to the varying interaction between the nonstructural components and the adjoining structure. These relationships are diagrammed in Figure 1, and outlined below.

In general, nonstructural damage is caused in two ways. The component may be directly affected by ground motion transmitted by the main structure of the building and be subject to accelerations and consequent inertial forces in a similar way to the building structure. Alternatively - or in addition - the nonstructural component may be affected by movement or distortion in the structural elements that support or abut the elements. These two causes can be summarized as acceleration or drift related damage: the complexities implied by these categorizations are worth exploring in more detail.

Nonstructural items may be located unattached on structure, in which case they will receive the accelerations and motion of their support. Depending on the item, it may reproduce the building motion, it may amplify it, or it may reduce it by sliding or rocking (simulating a degree of base isolation). Under certain circumstances of geometry and mass distribution it may overturn. In other words each item acts like an independent building, with varied "floor (or roof) interaction" that is analogous to the soil-structure inter-action of the whole building.

If the item is attached to the horizontal surface only (common in anchoring mechanical equipment, for example) then it will reproduce the building motion, and it may amplify it, but it is far less likely to rock, slide, or overturn. For heavy, squat, items like tanks or chillers, for which sliding or rocking is undesirable, and the building accelerations can be tolerated, such attachment is beneficial in avoiding failure.

If the item is attached to vertical 


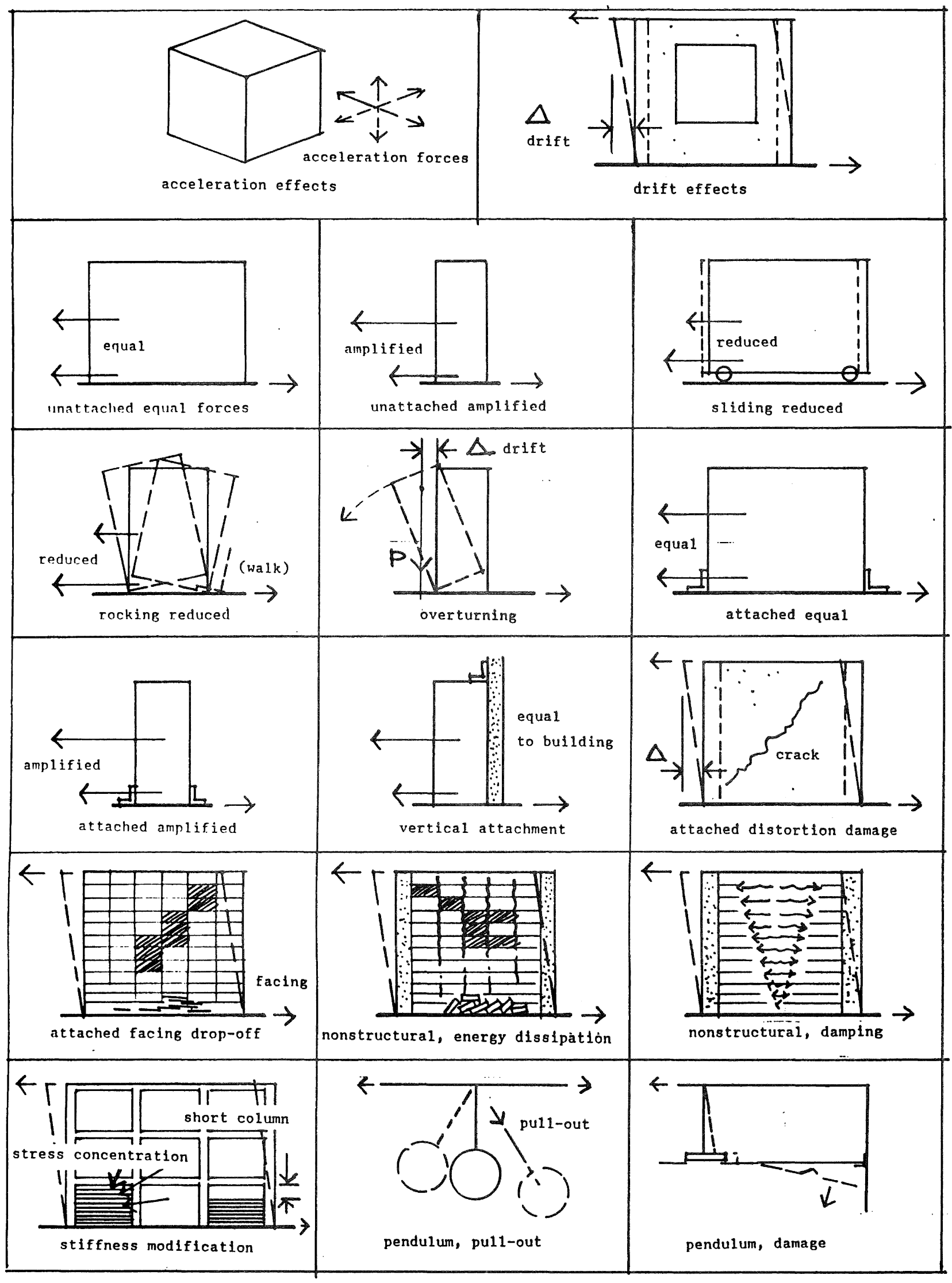

FIGURE 1 THE COMPLEXITY OF NONSTRUCTURAL EFFECTS 
structure, or is confined by vertical structure, it will reproduce the building motion, but is very unlikely to rock, slide, or overturn. Such an attachment is useful for items such as shelves and bookcases for which overturning is the typical cause of damage and loss. However, if the building structure distorts, then the non-structural element will in turn distort, and may well suffer damage. This is a typical cause of partition, plaster and wallboard cracking, and, short of elaborate detailing to detach the partition from its structural surround, not much can be done to prevent this damage. Depending on the use and material of the partition, the cost-beneficial approach is probably to accept the low risk of damage against the certain additional costs of detailing that may not, in fact, guarantee a damage free material.

As a further complication, if the nonstructural element has a facing, the movement of the nonstructural backing may stress the attachment and cause the facing to detach: depending on the material this may be costly or dangerous. Distortion of the building structure may represent elastic drift, which is commonplace, or inelastic distortion, which is less common, but is nevertheless an intended behaviour.

However, the confined or attached material will also, to a greater or lesser extent, modify the behaviour of the structural element to which it is attached, by:

* Increasing the energy dissipation capacity of the structural element (at the expense of the nonstructural material). This is intended behaviour, but generally not considered in analysis.

Increasing the damping capacity of the structural elements, and changing the period of the building. (This would represent a fairly extreme example of interaction). This is intended behaviour, but generally not considered in analysis.

* Changing the stiffness of the structural element, thus changing the distribution of forces within the structural system, and possibly causing unanticipated stress concentrations. This is unintended behaviour.

The extent to which the above takes place is primarily dependent on the mass and location of the nonstructural material. There could also be interactive effects in a tensile sense, but these are less likely to be significant.

If these interactive actions are to be taken seriously, we are in very deep analytical waters indeed, because of the number of variables and the lack of quantifiable information on performance at various drift. duration, and acceleration levels.

If the item is hung from the structure, it may act as a pendulum. If its motion and mass is significant, it may cause damage to its surroundings, or it may over stress its supports and drop. If it is a complex system such as a suspended ceiling, it may remain in place but become distorted, and in so doing allow portions of the assembly to fall.

As with the structure, the duration of the ground motion has a large effect on damage. Moreover, the structural response may increase the duration of motion in the upper floors of a building well beyond the duration of the motion at ground level.

\section{Nonstructural Components Damage Mitigation}

Methods of mitigating the damage to nonstructural components must recognize the probable mode of failure, whether through inertial forces or movement or failure in backing or abutting structures. For the former, nonstructural components must be designed in a similar way to the building structure, using an analysis of forces to determine bracing support requirements. For the latter, separation from back-up or abutting structures is necessary. Cladding must be designed to allow for movement of supporting frames, and heavy nonstructural walls must be detached from enclosing structure to allow for differential movement. Mechanical, electrical, and plumbing distribution systems must be secured to the building structure, with allowance for differential movement where applicable.

Most seismic codes deal with nonstructural components in a limited way and, in general provide procedures only for the first kind of failure mode noted above, that of forces due to ground motion. Thus, both the UBC and the NEHRP. Provisions provide seismic coefficients which, applied to a simple formula, result in an equivalent lateral force analysis for the nonstructural component.

\section{RECENT NONSTRUCTURAL PERFORMANCE IN 0.8. EARTHOUARES}

Against the background of the litany of potential damage and disruption outlined in the previous section, nonstructural performance in the 1989 Loma Prieta earthquake was perhaps remarkable for its lack of spectacular occurrences. There were minimal casualties (and no fatalities) from any cause. There was considerable glass breakage, but no showers of glass from downtown high-rises. Only one heavy exterior panel connection failure was recorded. No massive losses of computer-stored data were recorded, and few buildings suffered long-term functional loss that was unaccompanied by a considerable degree of structural failure.

The nonstructural damage reported at the Watsonville Community Hospital summarizes the $k$ ind of damage suffered in one of the most severely damaged high-service buildings in the area.

Watsonville Community Hospital was the closest hospital to the epicentre and it suffered more damage than any other medical facility. A summary of the nonstructural 
damage includes:

Communication. Internal communication disrupted, and telephone service at first interrupted, with sporadic service later. The paramedic base radio station was rendered unserviceable for 48 hours.

Power was lost for 26 hours before hand restoration. One of the diesel generators for emergency power broke off its mountings and was inoperable: the other sheared a fuel line and fuel had to be pumped by hand until repaired.

Elevators were unserviceable for three days.

A Liquid oxygen tank moved off its base, leaned at a 20 degree angle and leaked. The tank was within 50 yards of a 30,000 gallon propane tank.

The Computer system went off-line, cardiac monitors were non-operational, and televisions fell or were thrown from their mounts in patient rooms. The central air handlers on the roof were unserviceable, and there were multiple water leaks and partial flooding in a number of hospital locations.

Windows were broken on the fourth floor, and glass was on the floor throughout the hospital.

Some of the problems for individual departments were as follows:

CCU:

Evacuated due to broken windows and loss of elevators.

Pharmacy: Chemicals were spilled, refrigeration units fell, medication spillage, there was breakage of medications in glass containers, and loss of stock onto floor.

Radiology: Processor rendered unusable, spillage of processor chemicals onto floor, shelving units were wedged together, and records covered the floor.

Laboratory: All machines fell to the floor, floor surface was covered with spilled, mixed, uncontained chemicals and there was hazardous materials incident.

Central

Services: Considerable overhead flooding from broken cooling pipes, central service supplies as well as disaster patient tags and supplies stored in Central Services were inaccessible.

Dietary: Gas fumes, open gas lines, natural gas leaks, and refrigeration units toppled, spilling and spoiling food stock.

However, in spite of this considerable damage and disruption the hospital as a whole remained open and operational throughout the earthquake aftermath. During the first 24 hours there were 12 admissions to the hospital, and 17 patients were transferred by helicopter and ground transport. At the time of the earthquake there were 5 patients in the emergency room and 70 patients in rooms [4].

If, however, the overall incidence of spectacular and life-threatening nonstructural damage due to the Loma Prieta earthquake was small the total value of the damage was high. Unfortunately we do not know the exact, or even approximate extent of the total. Hundreds, perhaps thousands of buildings suffered damage to gypsum board partitions, to suspended ceilings, to wall and floor finishes, and to roof-top equipment. The causes of this damage, whether structurally related or independent, were little studied. Reports for damage claims do not reveal the origin of damage.

In addition, there were probably thousands of incidents of contents and equipment damage, from homeowners losing their collection of crystal to law libraries upsetting their reference collections. In most cases the cost of this damage is measured in the labour lost while the items are reassembled. In offices, the staff pitch in to rearrange their work areas and storage facilities. Some public libraries in san Francisco still have not been able to find the funds necessary for complete reshelving. The situation is made more complex in the main San Francisco library because a new library is in design, and so massive reshelving will be necessary in a few years anyway.

Some statistical studies have, however revealed some useful patterns of loss. The Building Owners and Managers Association (BOMA) of San Francisco surveyed 129 medium and large offices [51. Of these buildings, 9\% suffered structural damage, while $86 \%$ suffered nonstructural damage. The median dollar value of damage per building was $\$ 941120$. Of this, $\$ 66,500$ or $70 \%$ was water damage. This was categorized as $\$ 50,000$ sprinkler related, $\$ 5,000$ water supply related: and $\$ 11,500$ HVAC related.

The remainder of the median damage was divided into:

$\begin{array}{ll}\text { Imnediate clean-up: } & \$ 16,000 \\ \text { Elevators: } & \$ 3,080 \\ \text { Mechanical: } & \$ 3,540 \\ \text { Computer-related: } & \$ 5,000\end{array}$

The study also noted that $87 \%$ of the respondents reported elevator disruption. This averaged 35 hours, but for the most part was due to power outages in san Francisco. The state office of Health Planning and Development (OSHPD) reported that of the 428 hospitals in the affected area 282 (or 66\%) reported severe elevator disruption and 501 or (18\%), reported damage, which varied from bent guide rails to counter weights going through roofs. Loss of service time varied from 4 hours to 3 weeks $[6]$.

The BOMA study showed that sprinklers were a major cause of property loss. Specific incidents at some industrial plants reinforce this pattern, and the North 
Terminal at San Francisco Airport suffered several million dollars of property damage and a shut-down for several hours due to malfunctioning sprinklers. A study of sprinkler performance concluded that there was a 5\%-10\% failure rate in sprinkler systems [71. This rate compares to a $4 \%$ slight-to-severe damage in the heavy shaking area in 973 buildings in san Fernando, California in 1971 [81. The authors of the Loma Prieta report state that: "Most failures are of a localized extent, are quickly repaired, and are of minor consequence. - . Some specific failures have, however, resulted in multimillion dollar losses to building owners and occupants. These have been the result of water damage to structures, building contents, electrical power, controls, computer, and high-value goods in storage."

The nature of severe water damage is graphically illustrated by the description of a building damaged in the whittier Narrows earthquake of 1987 , quoted verbatim from the report [ 91 .

"The California Federal Data Processing center, located in Rosemead, California, was subjected to strong ground motions during the October 1, 1987 Whittier Narrows Earthquake $(M=5.9)$. The building was close to the epicentre. The building is a four story steel frame structure with concrete floors and concrete panel exterior walls, completed in 1962. The ground floor contains a large computer facility, office areas are located on the upper floors. The building sustained structural damage, consisting of two $\mathrm{K}$-braces in the steel framing buckled on opposite ends at the fourth floor; along the front of the building several wall panels partially detached from the steel framing; a crack developed across the width of the roof slab about midway through the building.

"Losses from nonstructural elements within the building far exceeded the structural damage, with water damage to the building interior from the fire suppression system one of the major losses. Smoke detectors, tripped either by dust suspended in the air from falling debris, or from short circuits created as the detectors collapsed with the suspended ceilings, resulted in the main deluge valve of the dry system opening, spraying water from fire sprinklers throughout the office areas. The fire suppression system also activated in the building elevators, just as the elevator lights went out and the elevators stopped between floors. One employee, trapped in an elevator, waited (with mounting concern) in the dark while water rose past knee level (she was released safely). A large amount of water poured into the upper floors of the building immediately following the main shock before the fire system could be valved shut. Water collected in cable troughs recessed in the concrete floors. The cable troughs assumed the role of water channels, directing the flow through electrical penetrations.

"The computer centre escaped serious shaking damage, and escaped direct water spray from the activated sprinklers because it is served by a halon fire system. However, water dripping from the upper floors found its way into the damaged ceilings above the computers. Plastic sheeting (part of the emergency plan) was used to cover the consoles and avoid water damage to the equipment."

Although over the whole area affected by the Loma Prieta earthquake glass damage was considerable, it was scattered and sporadic. only one large building suffered major glazing failure (about 10\%-15\%), this was a retail department store, which was constructed in 1946. Prior to the earthquake, the windows had been scheduled for replacement. Some injuries were sustained in the adjoining street, but these were not life threatening.

There was some damage to heavy cladding, but in only one reported instance, a public building in Redwood City, did a panel become partially detached (though it did not fall). However, there were many incidents of repairable spalling at panel interfaces and ends, which indicates that perhaps the motions were at the threshold of more serious damage.

The Morgan Hill (1984) and Mt. Lewis (1986) earthquakes resulted in considerable contents damage in the 13-story steel moment frame Santa clara County Services Building, though no other structural or nonstructural damage occurred (Figure 2). Heavy shelves that were braced following the first earthquake performed very well in the second quake [10].

The Santa Clara County Services Building again suffered considerable contents upset, but essentially no structural or nonstructural component damage. The forces in the Loma Prieta earthquake were considerably more than the building had experienced in its two previous earthquakes. Five levels of the building are instrumented: the peak acceleration at the roof was $16.9 \% \mathrm{~g}$ in the Morgan Hill earthquake, and $34.3 \%$ in Loma Prieta. Again, in Loma Prieta, contents upset was concentrated in the 7 th - 11th floors. A column on the 4 th floor showed some chipping and possible torsional response [11].

\section{THE SUMMING-UP}

As an example of the difficulties of assigning nonstructural damage, consider the building shown in Figure 3. This office building in Oakland displays considerable glass damage, and the brick facing has detached from the concrete backing (Figure 4). Is the glass damage due to incorrect detailing, or has the structure deflected to an extent that no detailing could tolerate? or, in looking at Figure 5, which clearly shows significant pounding from an adjoining building, has the glass been broken by the sudden impact, and the brick veneer dislodged by repeated sharp, out of plane accelerations? Is this a structural nonstructural, or pounding failure, and what mitigation measures could have prevented this from happening? 

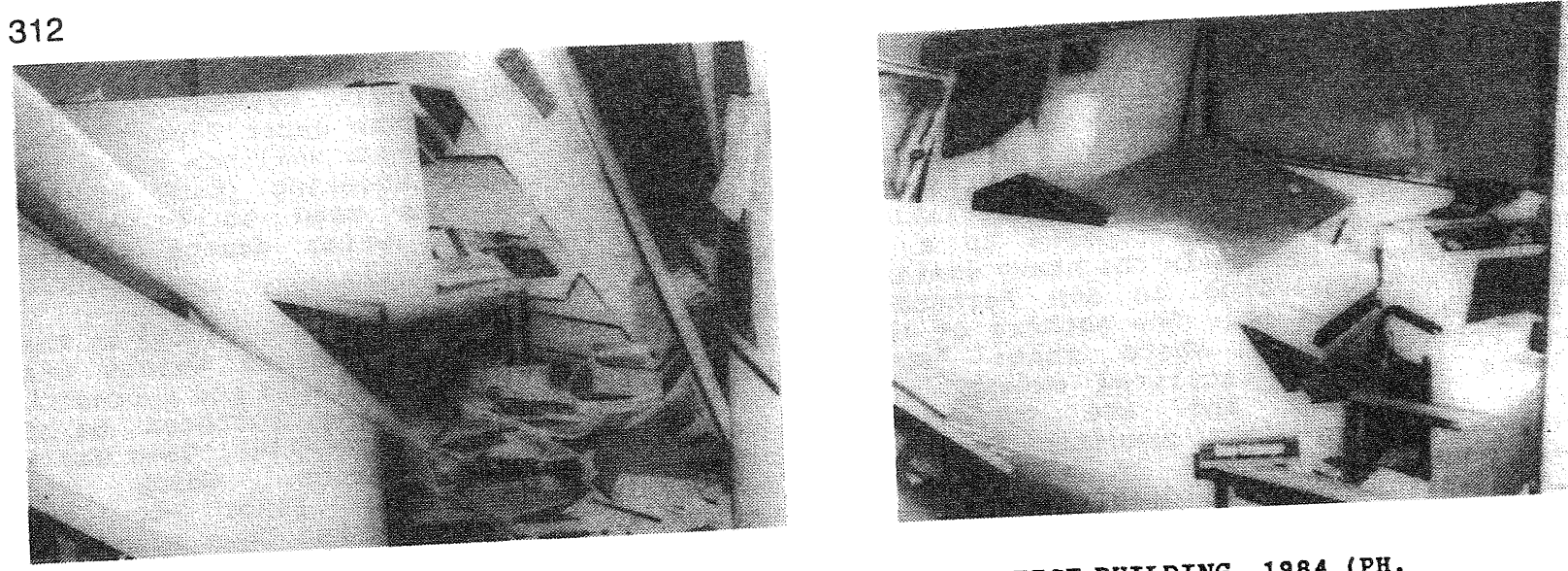

W. VANOSDOL)

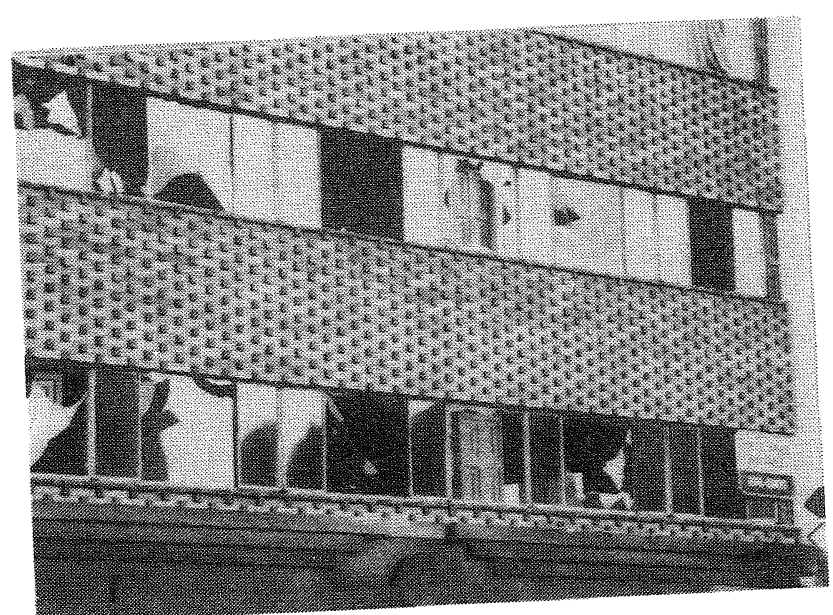

FIGURE 3 GLASS DAMAGE

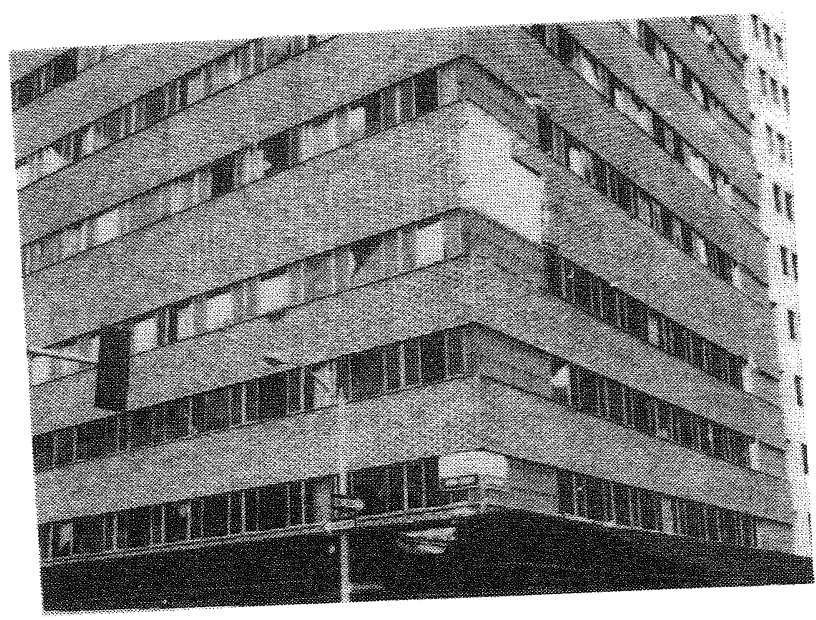

FIGURE - BRICK VENEER FAILURE

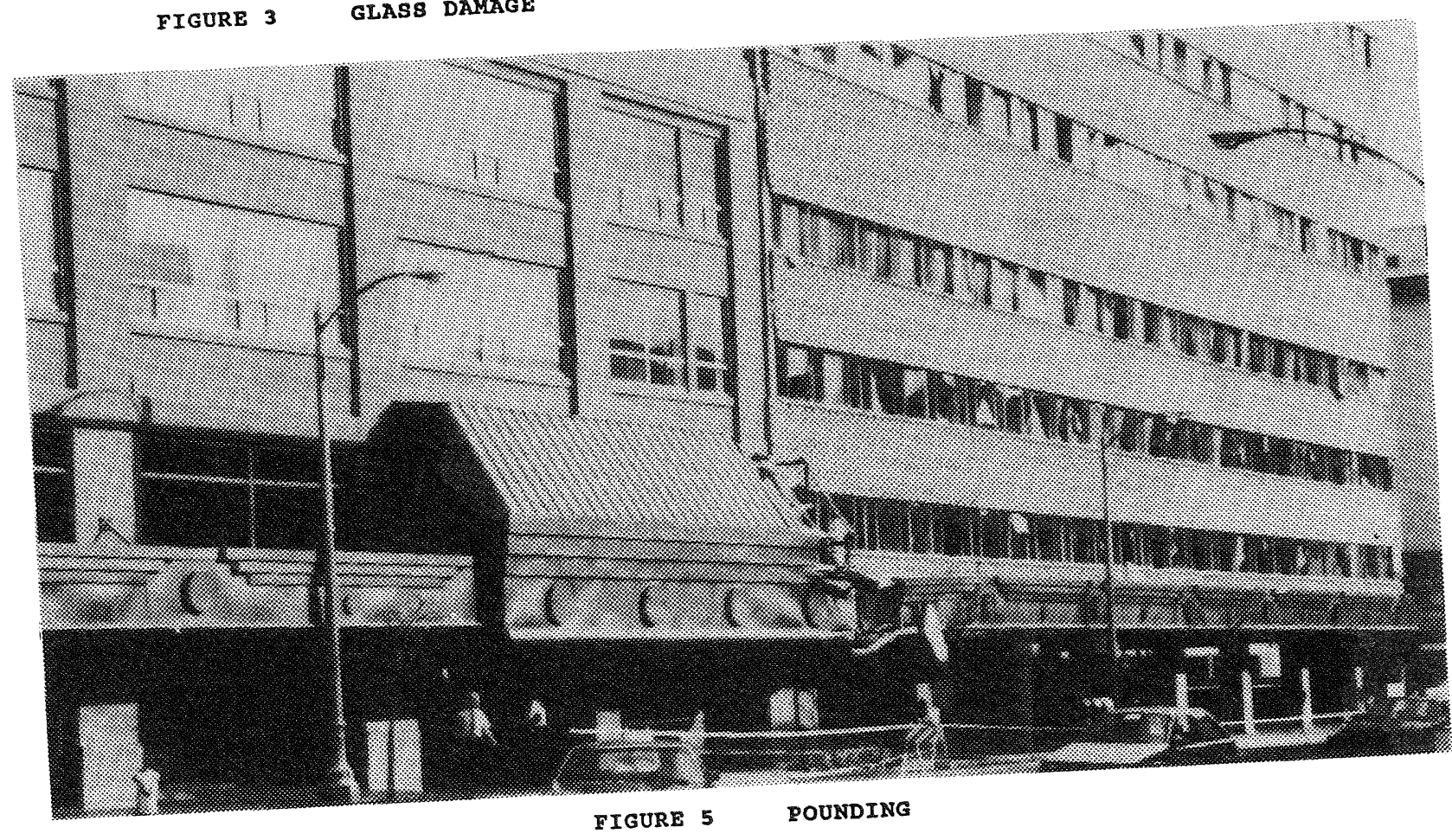


In the case of the Watsonville Hospital although it was the nonstructural damage that was most apparent, the building suffered so much structural failure that it will be replaced by a new structure. Perhaps this building met the intents of the code: it did not suffer collapse, and indeed remained functional to a large extent. Can we regard this performance as a success?

Notable in any detailed accounts of postearthquake building operation is a high degree of motivation and improvisation by staff. So for a building to remain functional is as much a managerial and human problem as it is a physical one. Consider, for example, another report of building damage in the whittier Narrows earthquake of 1987 [12].

The Ticor Title Insurance building was located in the city of Rosemead, very close to the earthquake epicenter. The building was a two story pre-cast concrete structure, with a steel deck roof. The building suffered severe structural damage to shear walls and diaphragms, considerable nonstructural damage to large cladding panels, which were seated on perpendicular walls, and much partition, glass, and ceiling damage. The building was constructed in 1978 on the basis of the 1973 UBC. At the time of the earthquake the building had two hundred occupants.

Notwithstanding the major structural and nonstructural damage, the facility was back in business the day after the earthquake: tents were erected in parking lots, and computer and telephone lines were run out to them. Temporary computer terminals, telephones, generators, fans, restrooms and eating facilities were installed outside. In the following weeks employees were relocated to other Ticor offices, temporary trailers replaced the tents in the parking lot, and other office space was leased.

This outcome was the result of fast, practical managerial decisions, many of which related to the fact that the owner had a number of other facilities in the state. In addition, however, many decisions related to the local physical situation, and knowledge of local resources such as tents and temporary services. And, of course, management and staff clearly worked together.

It has been pointed out many times that the current philosophy of the seismic code not only accepts nonstructural damage but in fact mandates it. The implications of this philosophy have been expressed by Porush [13]:

"Society's emphasis on protecting the lives of its citizens, and more importantly the fact that code design does not specifically prevent damage is evident from the fact that building code design of structures presumes ductile inelastic (post-yield) behavior. post-yield behavior in structural elements, by its very nature, implies that damage is being suffered in the form of cracking, permanent deformation, etc. Such behavior is not only tolerated, but encouraged as the optimun means of absorbing and dissipating the energy imparted to a structure by a major earthquake."

Clearly, then, the engineer's ready acceptance of ductility as a safeguard against collapse in the severe event is at the expense of the nonstructural components. Further, if we try to reduce damage by isolating our heavy components from the structure, we are defeating the engineer's intent. At an extreme, we may, by isolation, protect our components from damage in the elastic range, but sacrifice the main structure in the more extreme event.

A leading question is the extent to which the current philosophy (which by force level reduction encourages the design of flexible structures) leads to significant nonstructural damage in the moderate earthquake, with the structure deflecting elastically. It is clear from the Ioma Prieta experience that high-rise buildings appear to be safe structurally (for the Loma prieta motions) but that there is much contents upset. At a conservative estimate, in Loma Prieta, several million people experienced contents displacement and upset, together with frightening noise and motion, in their homes and places of work. Although as seismic designers we may dismiss contents upset in a high-rise building as inconsequential (compared to collapse), to the building occupant it is a terrifying and traumatic experience.

It is also clear that contents upset (except in specific cases such as libraries and other records centers) must be regarded as an inevitable post-earthquake nuisance: we are not going to eliminate it. There have been proposals to add damping to the santa clara building, but so far the damage has not justified the cost of such measures. We must explain to building occupants what is going to happen, encourage them to take self protective measures, and be prepared to pick up the messs. Our present designs for gypsum board partitions and hung ceilings must be regarded as replaceable components, and the occasional earthquake is similar in its effect to the occasional tenants remodel.

To what extent can our battery of mitigation measures (anchoring, bracing, bolting, isolating, etc.) be expected to reduce the incidence of non-structural damage? To the extent that architectural damage to ceilings, partitions, cladding and finishes is related to severe structural movement and distortion, not very much. Typical hung ceiling systems perform badly - tee-bars spread or pull away from wall supports, and acoustic panels drop. Current seismic codes require diagonal bracing, and that light fixtures must have safety wire attachments direct to the structure. However, for all the ceiling failures in Loma Prieta we have no systematic information on typical ceiling performance, the types of damage related to acceleration frequency and duration, the types of support, and the relative performance of code conforming ceilings and nonconforming. We do not really know whether our mitigation measures work at all. 

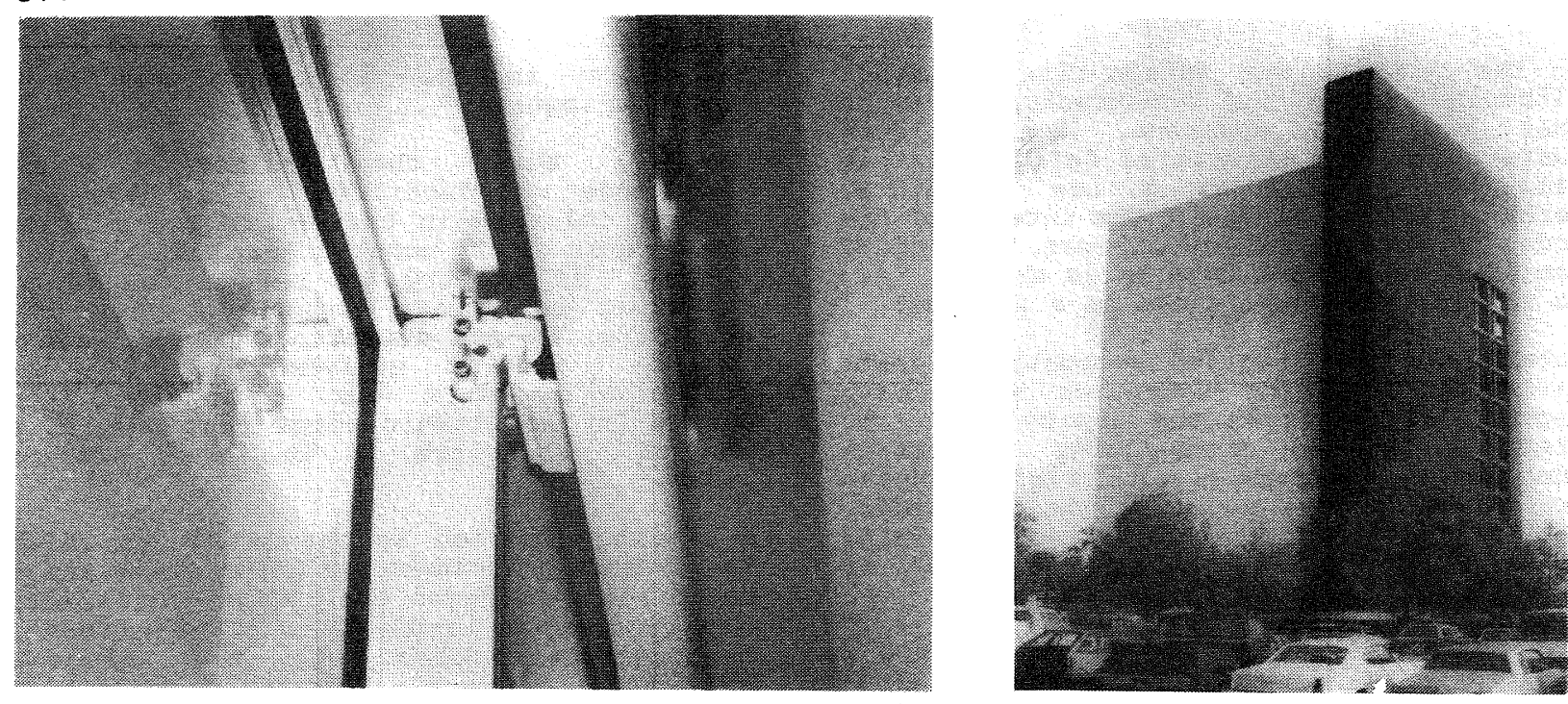

FIGURE 6 DETAIL OF CURTAIN WALL SUPPORT, SANTA CLARA OFFICE BUILDING (PH.

8. RIHAL)

However, our methods of installing cladding and glass seem to be quite effective, at least for the moderate shake. To return to the santa clara building (which is of particular interest because of the available records) the integrity of its all-glass curtain wall over three earthquakes has been a source of comment. Recent investigation shows that this wall appears to have been attached by use of an unusual and sophisticated detail which effectively isolates it from the steel supporting structure and permits differential movement (Figure 6).

Can we reduce the impact of utility failures and water damage, as instanced in Watsonville Hospital and in the BOMA report? Again, the problem is more one of structural and nonstructural interaction than the integrity of the individual system. Here we are handicapped by lack of detailed knowledge : systematically to investigate the causes of nonstructural damage is very labor intensive and, despite frequent appearance on research agendas, has not been done. Nor is it likely to be done in the forseeable future. Moreover, nonstructural damage mitigation has become a marketing opportunity since Loma prieta: the information on damage is disappearing into proprietary data banks and mitigation effectiveness is discussed more in sales brochures than in peer-reviewed research papers.

Improved detailing and installation of sprinkler systems, and increased bracing and anchoring of mechanical equipment will probably reduce the incidence of damage, but will not eliminate it. If a branch sprinkler head is going to be pounded by adjacent flexible structure or ceiling members it will ultimately fail. To institute truly coordinated analysis and detailing of structural and nonstructural components is, I believe, beyond our present capability for the typical building. while it may be done in the nuclear industry at great cost and with still undetermined effectiveness, the conditions met in these facilities are still relatively standardized and predictable compared to those encountered in the multiplicity of normal design and construction jobs.

Where protection against nonstructural damage is critical, whether for functional or business reasons, designers and owners are increasingly leaning towards baseisolation of the entire building. only by significantly changing the building response can there be reasonable assurance of mitigation of the nonstructural problem.

It is also, I believe, now clear that nonstructural damage is not the threat to life that conventional wisdom (as expressed in the initial litany in this paper) would have us believe. The probability of serious injury has alway been expressed more in speculation than in documentation. A recent research paper, based on over ten years of study of earthquake casualties, has had the courage to reach a tentative conclusion:

"One of the preliminary findings of our research - in physical setting aspects of injuries to date - is that nonstructural elements, building contents, and most physical settings have a low likelihood of causing serious injuries. If these findings continue to be confirmed, they will go against conventional wisdom and policy that all potentially hazardous nonstructural elements and building contents should be mitigated." [ 14$]$

In the absence of the systematic postearthquake study of nonstructural damage and the development of useful statistics that would enable patterns and priorities to be established with some assurance, nonstructural damage has been particularly 
subject to two laws that operate in the earthquake hazard mitigation field. These are :

1. "The Law of Low-Probability
Anecdotes":

This law states that the influence of an anecdote is directly proportional to its dramatic value and inversely proportional to its probability of reoccurence.

As an example of this consider the following anecdote from the Whittiler earthquake of 1987, which warns against the proliferation of effects from a small initial incident:

On the 8th floor of the Physical sciences Building at California state University Los Angeles a bottle of less than one gallon of kerosene containing sodium metal, which was located under a fume hood, was knocked over. A water lead from

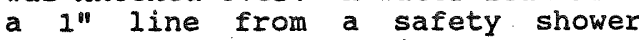
(which had been bjroken at a threaded connection during the saking) reacted with the sodium and the resultant hydrogen gas ignited. the overhead sprinkler system was non-operational, preventing the sprinkler system from extinguishing the fire. The apparatus grid in the room had mercury manometers attached which were destroyed and spread contamination. Finally, the fire and earthquake combined to create an asbestos problem that had to be cleaned up. The asbestos spill alone caused clean-up costs of $\$ 237,000[15]$

2. "The Law of Speculation":

In the absence of documented empirical evidence, dramatic speculation is equaliy valid as a policy instigator.

These kinds of speculation are rife, ranging from the destruction of st.Louis or Mephis in a repeat of the Missouri earthquake of 1811, to the collapse of the world banking system due to the destruction of financial data in a repeat of the 1906 San Francisco earthquake. Another popular myth is the failure of a major silicone valley firm due to the destruction of a company that is the sole supplier of a critical component.

Many other examples of these laws in action will be found in the body of this paper.

\section{REFERENCES}

1. Architectural and Nonstructural Aspects of Earthquake Engineering. 1987. UC Berkeley, Continuing Education in Engineering, University Extention.

2. Arnold, C. 1984. Nonstructural Issues of Seismic Design and Construction. Earthquake Engineering Research Institute.
Oakland, California.

3. Shipp, J.G. and Johnson, M.W. 1990 Seismic Loss Estimation for NonStructural Components in High-Rise Buildings. Proceedings. 4 th U.S. National Conference on Earthquake Engineering. Earthquake Engineering Research Institute, Oakland, California.

4. Estees, P.A. and Angell, L. 1990 Notes for the Hazard Reduction and Emergency Planning Conference. Hospital Council of Northern California.

5. Building Owners and Managers Association. 1990. Loma Prieta Earthquake Survey, San Francisco.

6. Staehlin, W.E. 1990. A Report to the Building Safety Board on the Performance of Hospitals in the Loma Prieta Earthquake of October 17 , 1989. State of California office of Statewide Health Planning and Development.

7. Harris, S.P. 1991. Fire Protection Systems: Post-Earthquake Experience and Reliability. ATC-29 Seminar on Seismic Design and performance of Equipment and Nonstructural Elements in Buildings and Industrial structures. Applied Technology Council. Redwood City, California.

8. Ayres, J.M. and Sun T-Y. 1973. Nonstructural Damage: The San Fernando California Earthquake of February 9, 1971. National Oceanic and Atmospheric Administration. Washington, D.C.

9. Scawthorn, C. Swan, S.W. Hamburger, R.O. Hom, S. 1991. Building Safety Systems and Post-Earthquake Reliability. ATC-29 Seminar: Seismic Design and Performance of Equipment and Nonstructural Elements in Buildings and Industrial Structures. Applied Technology Council. Redwood City, California.

10. Arnold, C. 1986. Occupant Behaviour Related to Seismic Performance in a High-Rise Building. Proceedings. Third U.S. National Conference on Earthquake Engineering. Earthquake Engineering Research Institute. Oakland, California.

11. Rihal, S.S. 1991. Correlation Between Recorded Building Data and Nonstructural Damage During the Loma Prieta Earthquake. California Department of Conservation. Division of Mines and Geology.

12. Estes, K. 1988. The Whittier Narrows, California Earthquake of October 1, 1987 - Ticor Title Insurance Building Damage. Earthquake Spectra. Volume 4, Number 2. Earthquake Engineering Research Institute. Oakland, california. 
13. Porush, A.R. 1991. An Overview of the Development of Current Code Requirements for Nonstructural Elements. ATC-29 Seminar. Seismic Design and Performance of Equipment and Nonstructural Elements in Buildings and Industriai structures. Applied Technology Council, Redwood city, California.

14. Durkin, M.E. and Thiel, C.C. 1992 Improving Public Policy to Reduce Earthquake Casualties. Earthquake Spectra (in press). Earthquake Engineering Research Institute. Oakland, California.

15. Taly, N. 1988. Performance of Buildings at California state University, Los Angeles. Earthquake Spectra. Volume 4, Number 2. Earthquake Engineering Research Institute. Oakland, California. 